\title{
DESENVOLVIMENTO DE GUINCHO TRANSFERIDOR COM FOCO NO DESIGN INCLUSIVO PARA IDOSOS COM MOBILIDADE REDUZIDA
}

\author{
Katharina Fernanda Silva Rios (UNIVERSIDADE FEDERAL DE ALAGOAS) \\ katharina.rios47@gmail.com \\ Juliana Leite da Silva (UNIVERSIDADE FEDERAL DE ALAGOAS) \\ julianaleitedasilva.j1@gmail.com \\ Yasmin Medeiros da Silva (UNIVERSIDADE FEDERAL DE ALAGOAS) \\ yasmin-medeiros23@hotmail.com \\ Juliana Donato de Almeida (UNIVERSIDADE FEDERAL DE ALAGOAS) \\ juliana.donato@fau.ufal.br
}

\section{Resumo}

A mobilidade reduzida é uma situação na qual determinada pessoa se encontra com movimentos limitados devido a idade ou deficiência física ou mental, e assim, necessita de atenção e adaptações nos ambientes e objetos. Por ser uma condição que atinge, em sua maior parte, idosos, como consequência do envelhecimento, é normal a redução da mobilidade das articulações, fraqueza e pouca agilidade. Ao passar por esse processo, as pessoas tornam-se dependentes da ajuda de cuidadores ou familiares para realizar atividades básicas. Sendo assim, o desenvolvimento de um guincho transferidor que auxilie na locomoção e/ou na execução de movimentos dos idosos com mobilidade reduzida, possibilitando um processo mais confortável para o usuário, será proposto, com foco no design inclusivo e uso de ferramentas metodológicas apresentadas por diversos autores, caracterizando uma metodologia híbrida.

Palavras-Chaves: Mobilidade reduzida; idosos; projeto de objeto; guincho transferidor; design inclusivo.

\section{Introdução}

De acordo com o Instituto de Pesquisa Econômica Aplicada (2018), dados divulgados pelo IBGE no ano de 2018 apontam que até o ano de 2060, o número de pessoas com mais de 60 anos deve chegar a $25,5 \%$ da população brasileira. Nesse contexto, cerca de $40 \%$ dos idosos, necessitam de auxílio para desenvolver tarefas em casa, como preparar refeições, limpar a casa e fazer compras, e $10 \%$ precisam de ajuda para realização de tarefas simples, como comer, tomar banho, ir ao banheiro, vestir-se, sentar e levantar (KARSCH, 2003 apud MEDINA, 1998). 
Diante dessas circunstâncias, iniciou-se o processo de busca pelas principais demandas para o referido público. A primeira etapa do projeto se deu através da realização de um brainstorming, (v. figura 1). Segundo Baxter (2000), por meio de sua utilização é possível gerar dezenas de ideias em apenas uma sessão. Durante o processo, foram citadas palavras relacionadas ao cotidiano de uma pessoa idosa, tendo foco em suas principais atividades desenvolvidas e dificuldades.

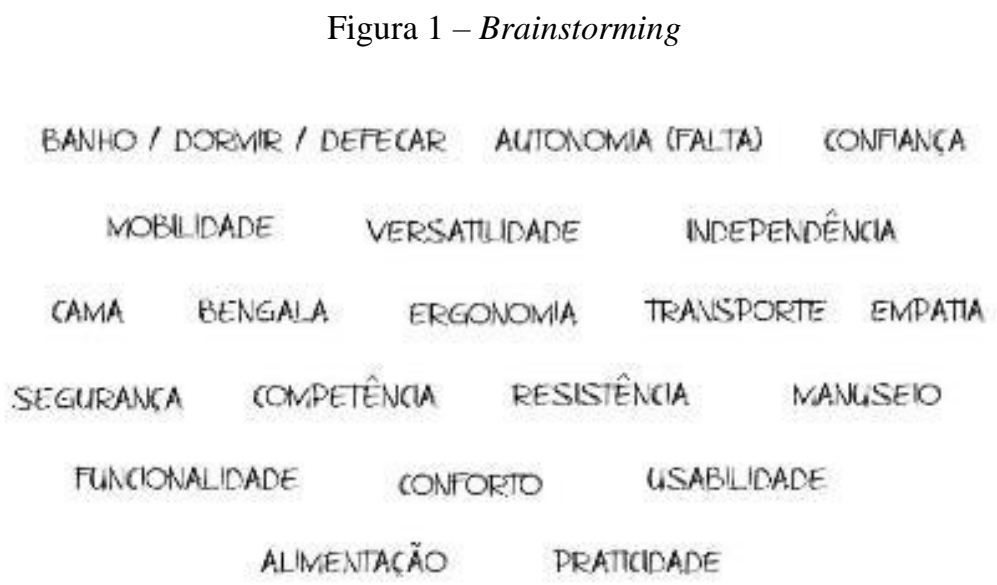

Fonte: Elaborado por autoras de acordo com pesquisa realizada (2019)

Em seguida, com o objetivo de organizar e resumir os dados obtidos através da pesquisa desk, (busca de informações em bases de dados sobre tema do projeto), e do brainstorming, foi elaborado um mapa mental (v. figura 2), ferramenta sistematizada por Buzan (2009), na qual permite um acesso rápido e fácil a informações importantes, possibilitando assim, armazenar, organizar e priorizar informações.

Figura 2 - Mapa mental



Fonte: Elaborado por autoras de acordo com pesquisa realizada (2019) 
Ao desenvolver o mapa mental foi avaliado o tema da mobilidade reduzida, seus possíveis problemas e soluções. Durante a execução da análise de informações para o mapa, chegou-se à definição de quatro pontos essenciais para o novo produto: conforto, confiança, praticidade e usabilidade. Para o desenvolvimento da fase informativa do projeto, foram utilizadas ferramentas propostas por diferentes autores - Baxter (2000), Buzan (2009), Bonsiepe (1984), Kim e Maubourgne (2004), Vianna et al. (2012), Design Thinking (2010), Kepner e Tregoe (1981), caracterizando uma metodologia híbrida. As etapas metodológicas tratam-se, à priori, da identificação das necessidades, na qual foram observadas as principais pendências no cotidiano de idosos e cuidadores, em seguida, a etapa de levantamento e análise de dados, na qual foram coletadas e analisadas informações acerca de mercado, público, material e utilização dos produtos, e por último, a identificação e indicação dos requisitos e parâmetros. Enquanto na fase projetiva, foram realizadas a geração das alternativas, seleção e dimensionamento da alternativa escolhida.

\section{Levantamento e análise de dados}

A etapa de levantamento de dados se trata do ato de recolher informações acerca do problema. Durante a análise, pôde ser identificada a problemática ao oferecer informações que podem vir a ser relevantes.

A partir da década de 70, o Brasil passou de uma sociedade predominantemente rural e tradicional para uma sociedade urbana, desse modo, enquanto a taxa de natalidade teve queda, o número de pessoas idosas passou a aumentar (MIRANDA et al, 2016). O envelhecimento acarreta problemas cognitivos e sensoriais que acabam dificultando a mobilidade física, o corpo fica mais frágil e dependente do auxílio de outras pessoas, levando o idoso à dependência. Nesse contexto, um indivíduo com mobilidade reduzida é aquele que:

Não se enquadrando no conceito de pessoa com deficiência, tenha, por qualquer motivo, dificuldade de movimentar-se, permanente ou temporariamente, gerando redução efetiva da mobilidade, flexibilidade,

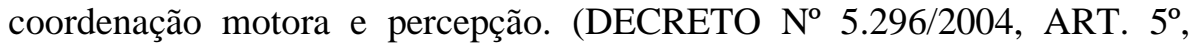
2004).

Logo, o espaço onde o idoso habita deveria se adaptar às suas necessidades, cabendo aos equipamentos proporcionarem conforto e segurança, entretanto, muitas vezes não é possível e como consequência acontecem acidentes. De acordo com Maconequi (2018), entre os mais frequentes estão as quedas, que são ocasionadas pela dificuldade motora de andar e de manter 
o equilíbrio, principalmente em ambientes como o banheiro, o qual se torna extremamente perigoso devido ao piso escorregadio.

No mercado é possível encontrar produtos que auxiliam em atividades diárias, entretanto, pesquisas apontam que idosos ainda sentem falta de produtos mais adequados a eles. Nesse sentido, de acordo com Gomes e Quaresma (2016), o design inclusivo trata de uma abordagem de projeto que busca integrar a diversidade de uso para várias pessoas, objetivando considerar o maior número de pessoas durante o processo de projetar.

\subsection{Análise de mercado}

Ao realizar a análise de mercado, buscou-se identificar demandas e lacunas de mercado e as principais características de produtos concorrentes que devem ser evitadas ou aproveitadas durante a geração de ideias.

\subsubsection{Análise paramétrica}

A análise paramétrica é utilizada para comparar produtos já existentes no mercado através de parâmetros comparativos quantitativos (v. figura 3) e qualitativos (v. figura 4). Os parâmetros qualitativos analisados tratam de medidas, peso do produto, o peso máximo suportado pelo mesmo e preço. Os critérios utilizados para análise dos produtos indicados foram baseados nas características apresentadas pelos fabricantes e sites de venda. De acordo com Baxter (2000), essa análise, ao identificar características satisfatórias presentes ou não em produtos concorrentes, o projetista pode incluir em seu projeto atributos que diferencie e atenda aos interesses do público e mercado. 
Figura 3 - Análise dos parâmetros quantitativos

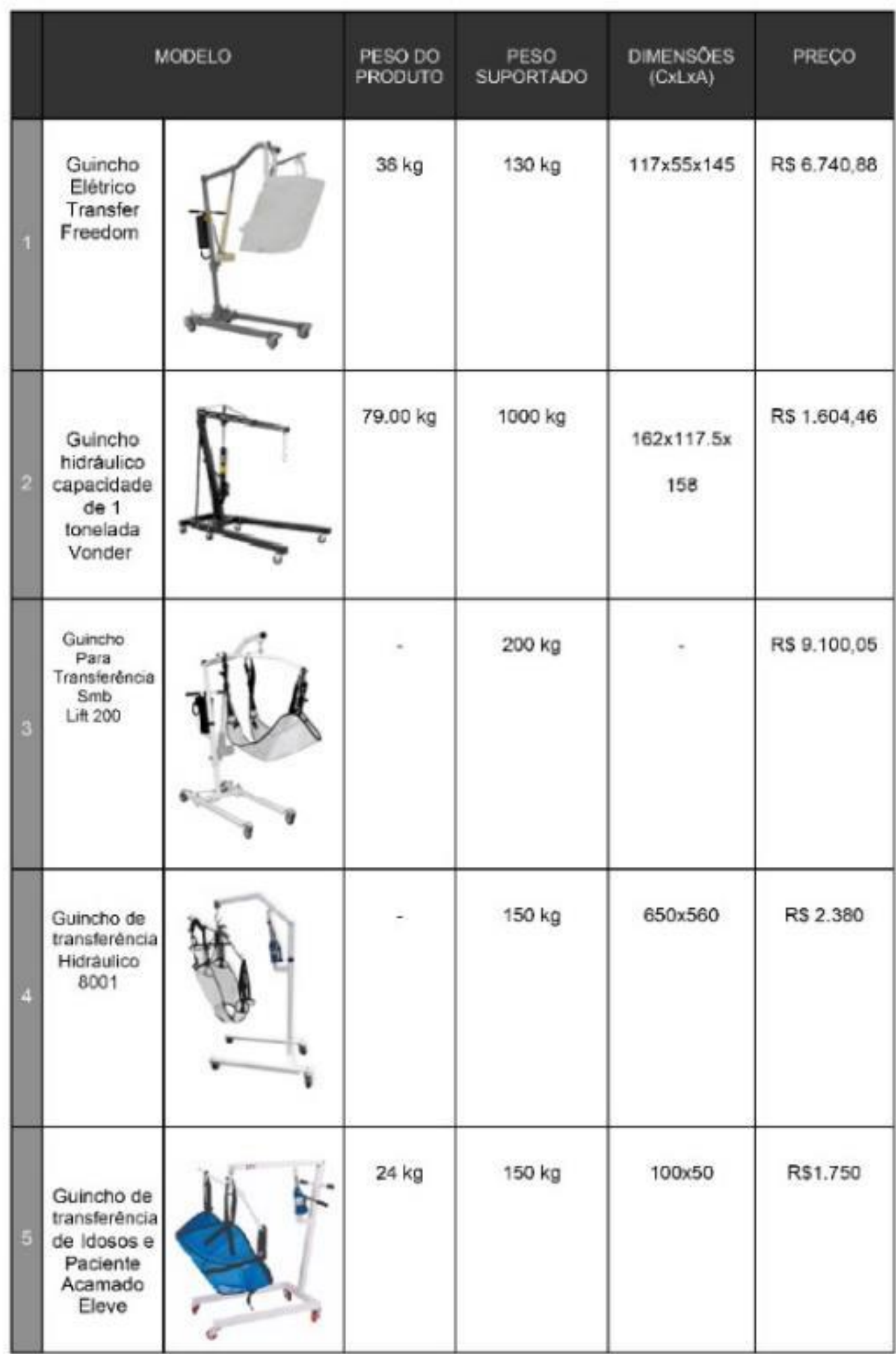

Fonte: Elaborado por autoras de acordo com pesquisa realizada (2019)

Os parâmetros qualitativos analisados nos produtos vistos no quadro anterior se tratam de variáveis como conforto, usabilidade, características presentes no produto e material. 
Figura 4 - Análise dos parâmetros qualitativos

\begin{tabular}{|c|c|c|c|c|c|}
\hline É elétrico? & Sim & Não & Sim & Não & Não \\
\hline Parece confortável? & Não & Não & Não & Não & Não \\
\hline Material & $\begin{array}{l}\text { Chassis em aço } \\
\text { carbono tubular com } \\
\text { pintura eletrostática } \\
\text { a pó desmontável }\end{array}$ & $\begin{array}{l}\text { Ferro acabamento } \\
\text { pintado que } \\
\text { proporciona maior } \\
\text { resistência à } \\
\text { corrosão/oxidação }\end{array}$ & - & $\begin{array}{l}\text { Estrutura em tubos } \\
\text { quadrados de aço } \\
\text { carbono }\end{array}$ & $\begin{array}{l}\text { Aço pintado com } \\
\text { tinta poliéster a pó }\end{array}$ \\
\hline $\begin{array}{l}\text { Possui travas nas } \\
\text { rodas? }\end{array}$ & Sim & Não & - & Sim & Não \\
\hline Tipo de uso & Individual & Individual & Individual & Individual & Individual \\
\hline
\end{tabular}

Fonte: Elaborado por autoras de acordo com pesquisa realizada (2019)

Como resultado da análise paramétrica, pôde-se perceber que boa parte dos produtos já existentes no mercado são semelhantes. Entretanto, a maioria apresenta como ponto negativo em comum a falta de conforto proporcionada ao usuário, o preço elevado e grandes dimensões do produto quando há necessidade de guardar em locais menores.

\subsubsection{Lista de verificação}

A lista de verificação, proposta por Bonsiepe (1984), realizada após a análise paramétrica, trata de listar características presentes em produtos concorrentes e dar notas - de 1 a 3 - a cada item, com o objetivo de encontrar pontos fortes que possam ser utilizados no produto a ser desenvolvido (v. figura 5). De acordo com o autor, esses atributos devem ser superados e os erros encontrados devem ser corrigidos.

Figura 5 - Lista de verificação com notas

\begin{tabular}{|c|c|c|c|c|c|c|}
\hline CRITERIO & PRODUTO 1 & PRODUTO 2 & PRODUTO 3 & PROOUTO 4 & PRODUTO 5 & \\
\hline Presence de cesto & 3 & 1 & 3 & 5 & 3 & \\
\hline $\begin{array}{l}\text { Prosensa de elastoma } \\
\text { sistrice }\end{array}$ & 3. & 1 & 3 & 1 & 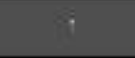 & \\
\hline Rodas com travas & 3 & 1 & 1 & 3 & $\therefore$ & \\
\hline Regulagem de albura & 1. & 1 & 1 & 1 & 4 & \\
\hline $\begin{array}{l}\text { E srticulado (pode } \\
\text { dohrar) }\end{array}$ & 3. & 1 & 3 & 1 & 1. & \\
\hline $\begin{array}{l}\text { Costo com apcio } \\
\text { para parnas }\end{array}$ & 1. & 1 & 1 & 1 & 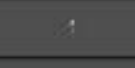 & $\begin{array}{l}\text { nđo atende os otende o necessidode } \\
\text { be manekra poyco efikiente }\end{array}$ \\
\hline $\begin{array}{l}\text { Resistencia do } \\
\text { muterial }\end{array}$ & 3. & 2 & 1 & 3 & 4 & $\begin{array}{l}2 \text { alende a necessibade do } \\
\text { monetra intermedióno }\end{array}$ \\
\hline $\begin{array}{l}\text { Faellicade de } \\
\text { manusear }\end{array}$ & 3. & 2 & 3 & 2 & 2 & $\begin{array}{l}3 \text { olende a necessidecte de } \\
\text { mancira boo ou kleal }\end{array}$ \\
\hline
\end{tabular}

Fonte: Elaborado por autoras de acordo com pesquisa realizada (2019) 
Portanto, concluiu-se que os produtos apresentados carecem nos critérios de regulagem de altura, cesto e o fato de não ser articulado, pois atendem a necessidade de maneira pouco eficiente ou não atendem, entretanto, possuem como ponto forte a facilidade de manuseio.

\subsubsection{Análise de custo benefício}

A análise do custo-benefício (v. figura 6), serve para organizar em forma de gráfico, os produtos, pesquisados na análise paramétrica, que possuem o menor/maior preço e melhores benefícios a proporcionar ao cliente. Os produtos foram selecionados e analisados de acordo com a diferença de preço, sendo escolhidos entre a faixa de preço de $\mathrm{R} \$ 1.600,00$ a $\mathrm{R} \$ 9.000,00$, o que consequentemente influencia questões que estão atreladas ao benefício na aquisição do produto.

Figura 6 - Gráfico de análise de custo benefício

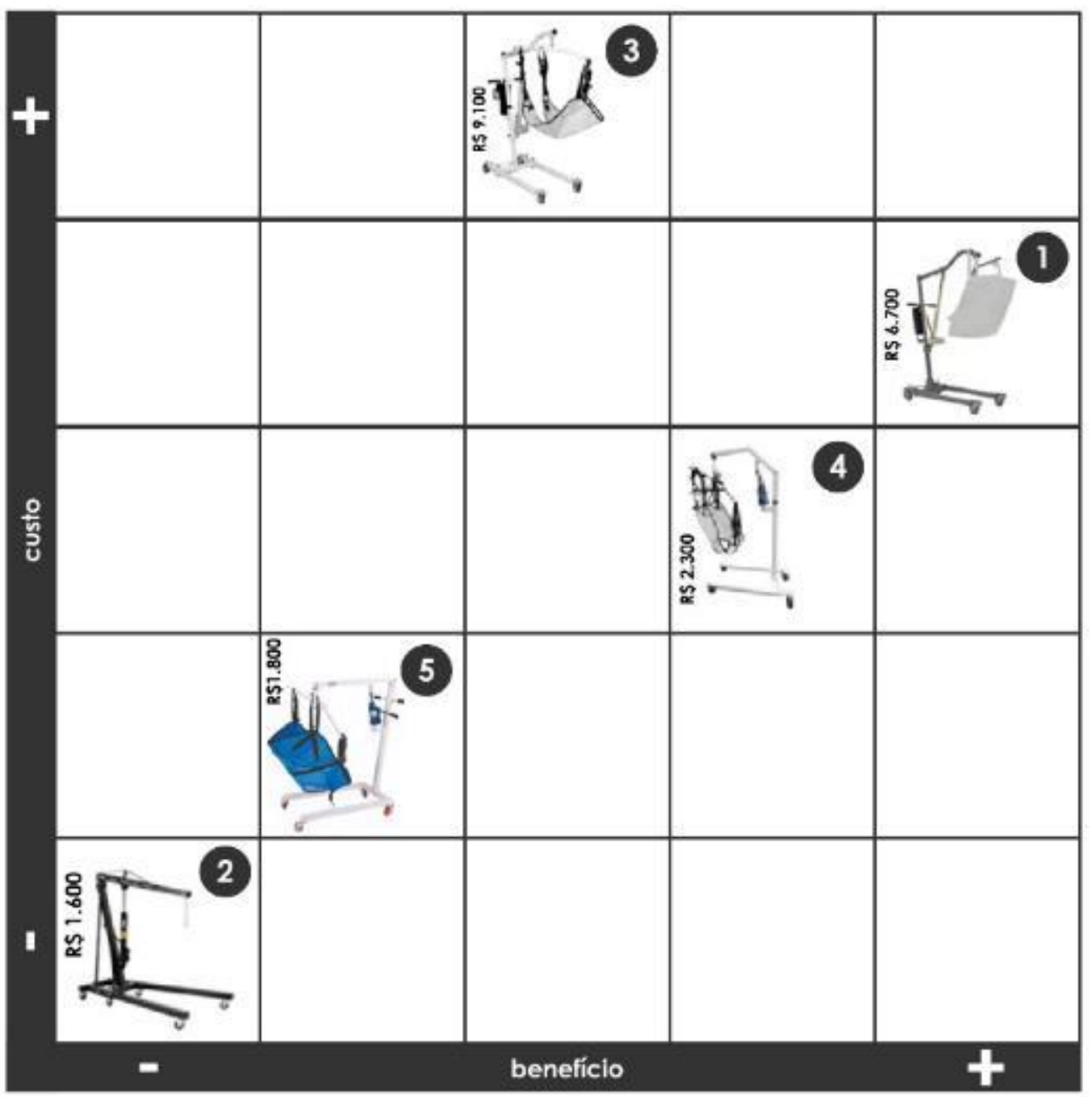

Fonte: Elaborado por autoras de acordo com pesquisa realizada (2019) 
Através do gráfico de custo benefício é possível identificar o melhor do mercado para que a partir dele seja desenvolvido o novo produto. Como resultado dessa análise, o produto 4 teve melhor desempenho, apesar do produto 1 alcançar o limite máximo em relação ao benefício, o valor dele no mercado é três vezes maior que o de número 4.

\subsubsection{Oceanos azuis}

A ferramenta metodológica Oceanos Azuis (Kim e Mauborgne, 2004), auxilia na exploração de um mercado desconhecido, no qual serão avaliadas as estratégias que a concorrência seguiu para se manter no mercado, junto as suas falhas, para que a partir daí, sejam criadas novas estratégias para o novo produto, propiciando um maior tempo de vida no mercado. Nela, o mercado é dividido em duas partes: oceano vermelho e azul. O vermelho é o mercado existente e conhecido, já o azul, trata-se dos mercados inexplorados ou que ainda não existem. $\mathrm{O}$ vermelho é onde as empresas buscam superar a concorrência de todas formas, reduzindo o lucro e a capacidade de crescimento deste. Enquanto no oceano azul a concorrência se torna irrelevante, já que se possui um mercado de criação de demanda, sem regras definidas e mais lucrativo. A matriz de avaliação de valor (v. figura 7) faz o diagnóstico permitindo analisar a situação atual do mercado.

Figura 7 - Matriz de avaliação de valor



Fonte: Elaborado por autoras de acordo com pesquisa realizada (2019) 
No eixo horizontal são apresentados os requisitos nos quais o setor está competindo e investindo, enquanto no eixo vertical é retratado o nível de oferta do atributo de acordo com a percepção dos compradores. Pontuando os atributos na matriz é possível compreender os perfis estratégicos e obter a chamada "curva de valor", a qual é uma representação gráfica da performance do produto a ser desenvolvido, e de seus concorrentes, em cada atributo.

\subsection{Análise de público}

Durante a análise de público são analisadas as principais características, necessidades e desejos do público que é consumidor do produto, visando entender e classificar a relação entre o usuário e o objeto.

\subsubsection{Personas}

Segundo Vianna et al. (2012), através das Personas, é possível representar desejos, motivações, expectativas e necessidades de um perfil de usuário para o qual serão desenvolvidos os produtos. As personas desenvolvidas criam uma situação hipotética, na qual um idoso sofre um acidente e se torna paraplégico, necessitando da ajuda de uma cuidadora e da neta para realização de tarefas básicas (v. figura 8).

Figura 8 - Personas desenvolvidas
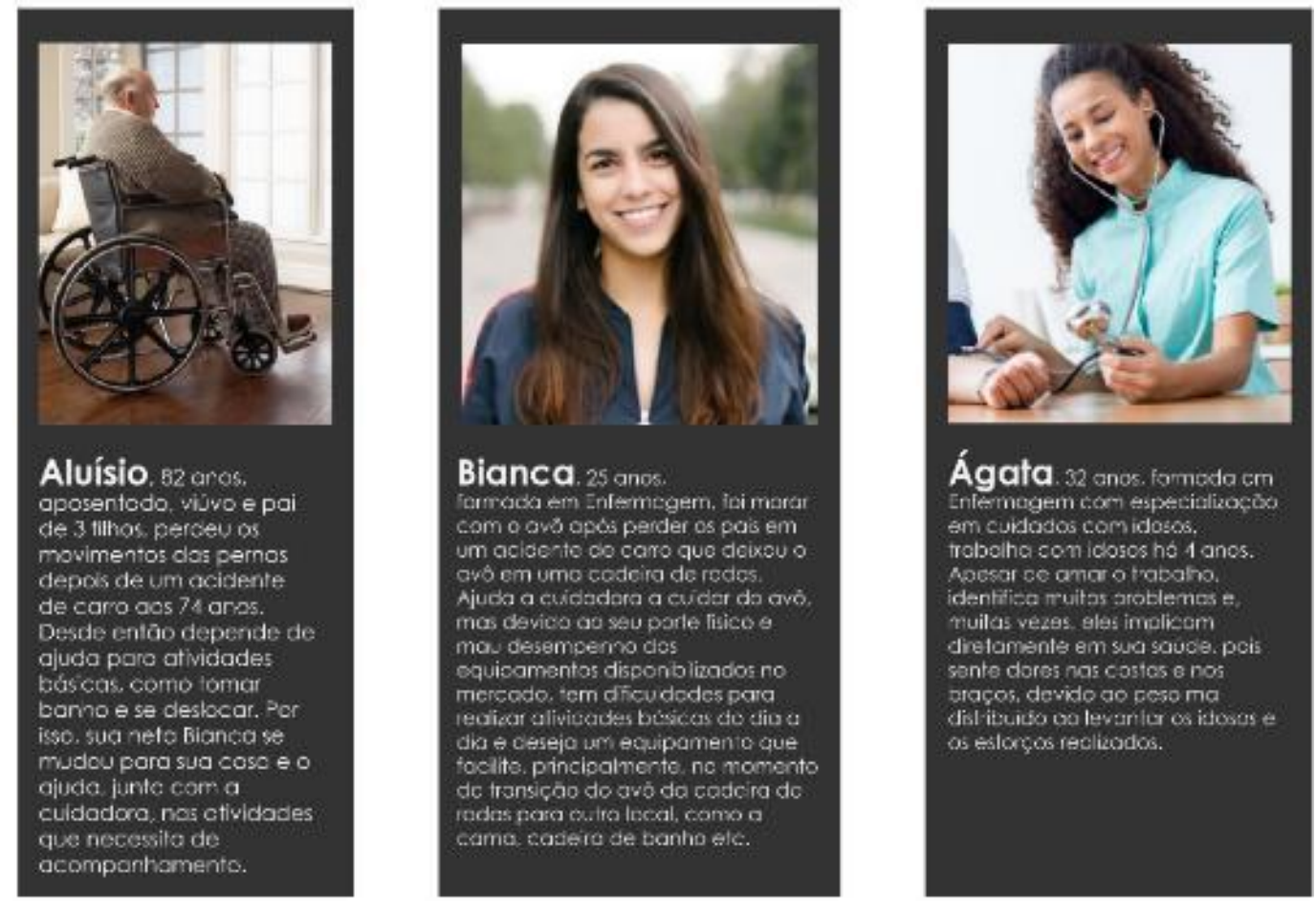

Fonte: Elaborado por autoras de acordo com pesquisa realizada (2019) 
Foi possível transmitir por meio das personas a realidade de muitas famílias. Independente de ter ajuda de cuidadores, há muita dificuldade no momento de transferir os idosos de um local para o outro, visto que os idosos geralmente possuem peso elevado e as pessoas que cuidam dos mesmos geralmente são mulheres, que por sua vez, não possuem tanta força nos membros superiores.

\subsubsection{Entrevista e mapa de empatia}

Como forma de ampliar as informações levantadas acerca do cotidiano de uma pessoa idosa com mobilidade reduzida, foi elaborada uma entrevista com perguntas acerca das atividades praticadas no dia a dia, suas principais dificuldades e práticas que não lhe requerem tanto esforço. O mapa de empatia (v. figura 9) (Brown, 2010), busca sintetizar as informações acerca do que ele pensa, sente, diz e faz, possibilitando a organização dos dados coletados na entrevista.

Figura 9 - Mapa de empatia

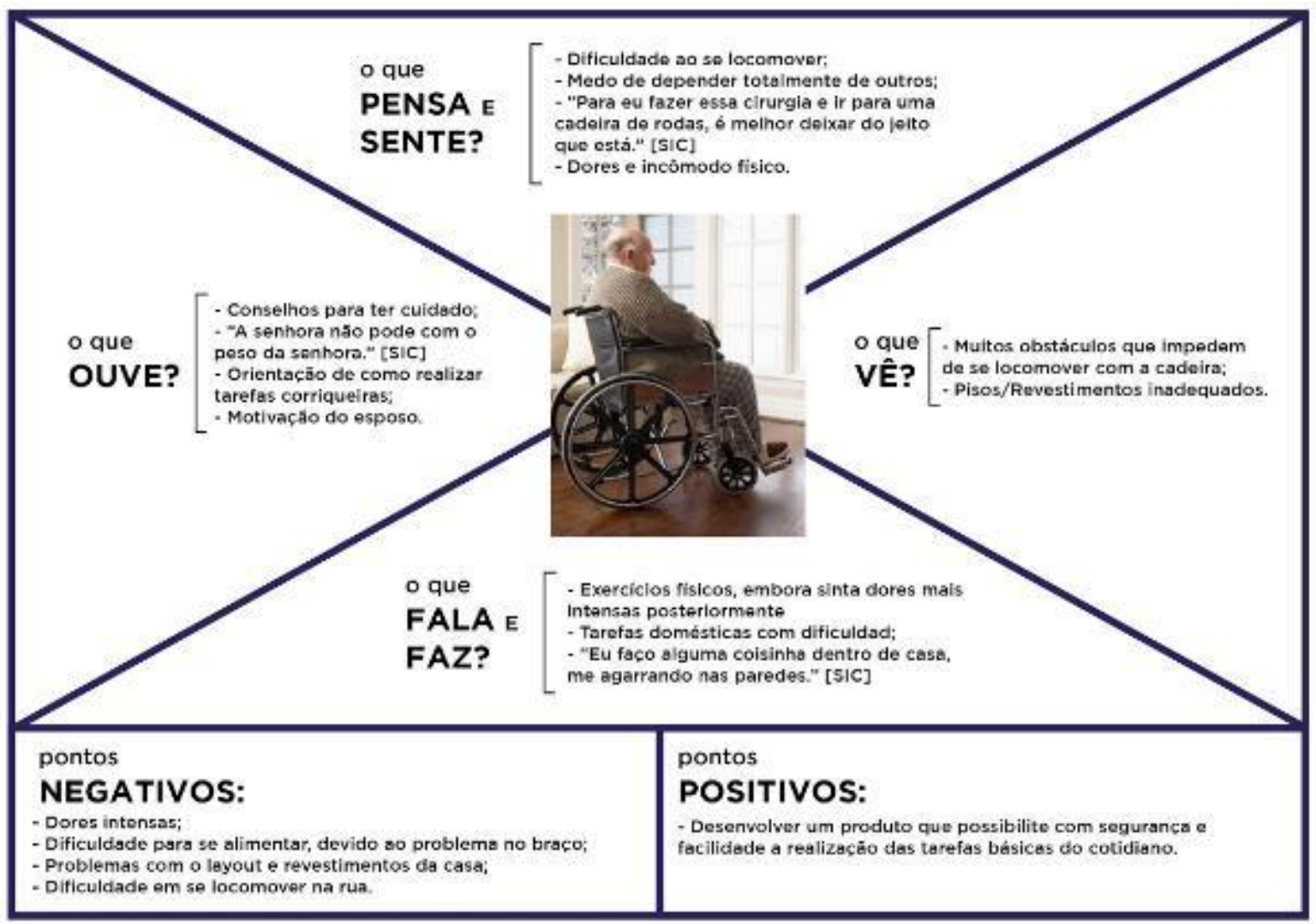

Fonte: Elaborado por autoras de acordo com entrevista realizada (2019) 
Como principais pontos destacados no mapa de empatia, pode-se perceber a queixa recorrente de dores e dificuldades na realização de tarefas básicas, mesmo havendo necessidade de fazê-las.

\subsubsection{Análise estrutural}

A análise estrutural serve para reconhecer e compreender, basicamente, a carcaça de um produto, seus tipos e o número dos componentes, subsistemas, princípios de montagem e tipologia de uniões (BONSIEPE, 1984).

\subsubsection{Análise morfológica e funcional}

Ainda segundo Bonsiepe (1984), na análise morfológica é permitido reconhecer e compreender a concepção formal e a composição de um produto, sendo analisado o produto 4 da análise paramétrica realizada anteriormente (v. figura 10).

Figura 10 - Análise morfológica do produto 4 da Análise paramétrica



PÉs 
Como destacado, boa parte dos produtos presentes no mercado possui características similares, sendo elas formas retilíneas e cores neutras. A superfície dos produtos geralmente é lisa devido ao acabamento do metal, enquanto o cesto possui superfície similar a uma tela, se tornando desconfortável para o idoso e não sendo higiênico.

Também proposta por Bonsiepe (1984), a análise funcional é utilizada para compreender as características físicas de um produto, incluindo aspectos ergonômicos - a macroanálise, e funções técnicas e físicas dos componentes do produto - a microanálise, podendo ser analisadas a funções primária e secundária. A função primária do produto analisado se trata de transferir o paciente com mobilidade reduzida, de locais como cadeiras, camas, bancos e entre outros. Já a função secundária pode ser vista como facilitar o processo de transferência para o cuidador e possibilitar mais conforto para o paciente. Desse modo, pôde-se concluir que os pontos imprescindíveis do projeto são a segurança durante o uso do objeto por parte dos idosos e dos cuidadores e o conforto do cesto.

\subsubsection{Análise de material}

A escolha de materiais levou em consideração a análise de mercado, já que os produtos existentes no mercado possuem o metal como material principal utilizado na estrutura. Segundo Lima (2006), o metal é um elemento químico que apresenta elevada dureza, resistência à tração e compressão, podendo ser classificados em dois grupos: ferrosos (metal no qual o ferro predomina em sua composição) e não-ferrosos (compreendem aos demais metais). Nesse contexto, o alumínio, classificado como não-ferroso, destaca-se pela sua versatilidade de uso, flexibilidade e transformação. Além disso, suas principais características são a autoproteção a corrosão, elevada condutibilidade elétrica e térmica e boa elasticidade, porém, é pouco resistente à tração. Entretanto, apesar das vantagens citadas, torna-se custosa sua utilização devido à complexidade do processo e gasto de energia necessários para sua obtenção. Além dos metais, outro material que se sobressai no mercado é a fibra de carbono, geralmente utilizada na fabricação de embarcações e aeronaves, por sua alta resistência mecânica e rigidez, além de ser considerado um material extremamente leve.

Ao observar os produtos da Análise de mercado, pôde-se perceber o uso do metal em todas as opções, principalmente devido a sua resistência, já que é necessário levantar grande quantidade de peso e, sobretudo, evitar acidentes. Deste modo, os materiais analisados estão dentro dos 
padrões desejados para desenvolver uma estrutura segura, leve e resistente, tendo em vista um produto para uso contínuo.

\subsubsection{Análise ergonômica}

A análise ergonômica tem como principal objetivo analisar as condições de trabalho de usuários, e objetos utilizados, ao realizar uma determinada tarefa, observando todos os aspectos relacionados a mesma. Nessa etapa, foi estudada a análise da tarefa com o intuito de entender melhor quais as principais dificuldades do idoso e do cuidador.

\subsubsection{Análise da tarefa}

De acordo com Baxter (2000), é imprescindível a análise da interação entre o produto e o usuário, visando melhorar a relação homem-produto e aspectos ergonômicos e antropológicos, pois, de certa forma, todo produto é projetado para o uso do homem. Sendo assim, durante a Análise da tarefa (v. figura 11), foi feita uma análise do usuário no momento de realização da sua tarefa e enquanto utiliza objetos, observando como ele lida com a atividade. Para sua realização, foi observado um vídeo retirado da internet e feitas capturas de tela para identificar

e destacar problemas biomecânicos, de postura, alcance, esforços, movimentos e de usabilidade. Para a transferência de pessoas feita com guincho, é necessário seguir os seguintes passos: 
Figura 11 - Análise da tarefa

(1) travar a cadeira de rodas
6 puxar as laterais do cesto e
11 direcionar a guincho para o local de prendé-las nas pernas do destino ao qual o idoso será levado
2 dobrar o cesto de maneir que facilite a colocaçăo
7 erguer as alças de cima do cesto
12 posicionar o guincho no locale
3 inclinar o idoso para frente
8 posicionar o guincho proximo da cadeira
13 retirar as alças do guincho
4 encaixar o cesto em suas costas
9. prender as alças no guincho
14 retirar a cesto e deixar o idoso confortável
5 inclinar o idoso novamente para trás
(10) erguer o idoso da cadeira
15 guardar o cesto

Fonte: Elaborado por autoras de acordo com pesquisa realizada (2019) 


\subsubsection{Projeto conceitual}

Produtos devem ser pensados com o intuito de transmitir emoções e sentimentos ao usuário, e segundo Baxter (2000), para conseguir isso, podem ser utilizados painéis imagéticos. Através das imagens dos três painéis, pode-se identificar o estilo de vida do consumidor, a expressão do produto e o tema visual do produto a ser desenvolvido. No painel de estilo de vida (v. figura 12), são apresentadas atividades diárias do público alvo, evidenciando a dependência dos cuidados de terceiros.

Figura 12 - Painel do estilo de vida



Fonte: Elaborado por autoras de acordo com pesquisa realizada (2019)

Já no painel de expressão do produto (v. figura 13), é representado através de imagens a sensação que o produto deverá passar para o usuário, neste caso, expressar o sentimento de conforto, autonomia e segurança.

Figura 13 - Painel de expressão do produto



Fonte: Elaborado por autoras de acordo com pesquisa realizada (2019) 
Por fim, no painel de tema visual (v. figura 14) são apresentadas imagens que expressam cores, texturas e formas que serão adotadas no projeto, representadas pelo alumínio, fibra de carbono, materiais confortáveis para o cesto e o formato dos membros inferiores dos flamingos - com base no estudo da biomimética, área da ciência que estuda as estruturas biológicas e suas funções, procurando entender as estratégias e soluções da natureza.

Figura 14 - Painel de tema visual

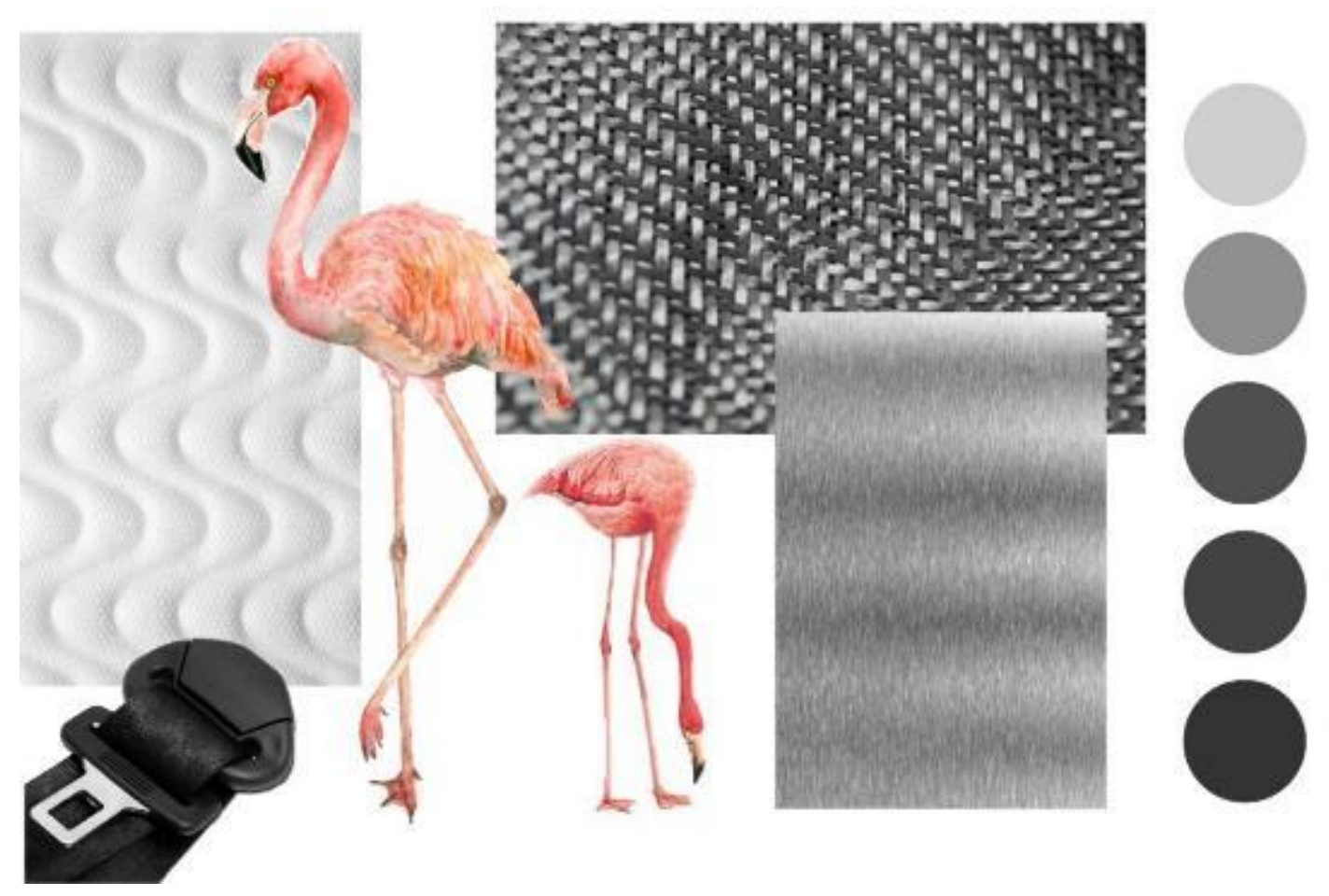

Fonte: Elaborado por autoras de acordo com pesquisa realizada (2019)

Desse modo, através da construção dos painéis foi possível construir o conceito do produto a ser desenvolvido. Neste caso, o conceito está atrelado, principalmente, ao conforto e segurança, para os idosos e para os cuidadores.

\section{Requisitos e parâmetros}

Os requisitos e parâmetros definem as direções para a concepção de um produto, utilizando como base os dados analisados posteriormente. Os requisitos se tratam dos atributos exigidos, enquanto os parâmetros são as medidas de referência utilizadas para suprir os requisitos. A seguir serão explanadas acerca das principais pendências identificadas nos produtos analisados na análise de mercado. 


\subsection{Matriz de GUT, geração de alternativas e matriz de seleção de oportunidades}

A Matriz de GUT - Gravidade, Urgência e Tendência, é uma ferramenta proposta por Kepner e Tregoe (1981), na qual serve para analisar e pontuar os problemas de acordo com a Gravidade, Urgência e Tendência. Os problemas analisados, durante a análise paramétrica, foram pontuados pela equipe com base na pesquisa realizada e de acordo com uma escala de 1 a 5 , do menos grave ao mais grave/urgente/tendencioso (v. figura 15).

Figura 15 - Matriz de GUT

\begin{tabular}{|c|c|c|c|c|c|c|}
\hline PROBLEMAS & GRAVIDADE & URGENCIA & TENDÊNCIA & $G \times U \times T$ & & \\
\hline A & 5 & 5 & 5 & 125 & & \\
\hline$B$ & 5 & 4 & 3 & 60 & A & Falta de travas nas rodas \\
\hline c & 5 & 5 & 5 & $125^{*}$ & B & Cesto desconfortável \\
\hline D & 2 & 2 & 2 & 8 & 2 & Falta de estabilidade \\
\hline$E$ & 3 & 2 & 1 & 6 & E & Precoeleyado \\
\hline$F$ & 3 & 3 & 1 & 9 & F & Năo é compatto \\
\hline
\end{tabular}

Fonte: Elaborado por autoras de acordo com pesquisa realizada (2019)

Após a realização do levantamento e análise de dados, identificando as principais dificuldades e necessidades dos usuários, e da matriz de GUT, foram geradas as alternativas do produto a ser desenvolvido (v. figura 16).

Figura 16 - Geração de alternativas
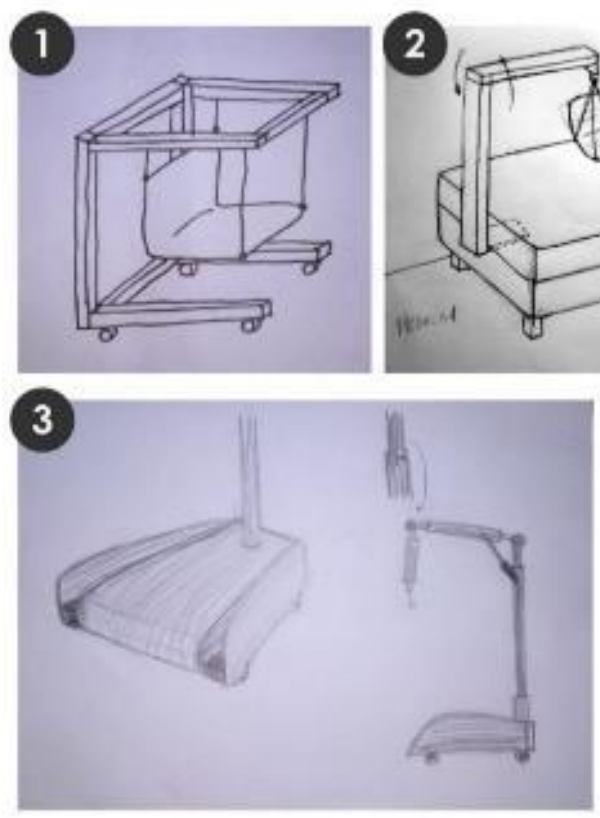

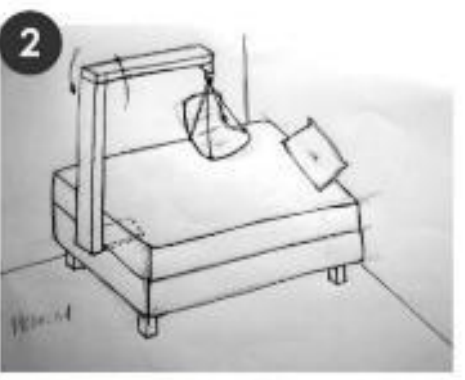

4

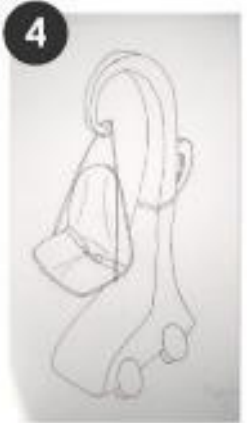


Proposta por Baxter (2000), essa ferramenta auxilia o projetista a identificar se o produto já existente no mercado - produto 4 da análise paramétrica, possui os problemas listados na Matriz de GUT e como ele se comporta de acordo com esses problemas, propondo notas de acordo com o peso descrito na tabela (v. figura 17).

Figura 17 - Matriz de seleção de oportunidades

\begin{tabular}{|c|c|c|c|c|c|c|}
\hline $\begin{array}{l}\text { CRITÉrio } \\
\text { DE SELEÇĂo }\end{array}$ & $\begin{array}{c}\text { PESO } \\
\text { DO CRItÉrio }\end{array}$ & REFERENCIA & ALTERNATIVA 1 & ALTERNAIIVA 2 & ALTERNATIVA 3 & ALTERNATIVA 4 \\
\hline A & +2 & +2 & +2 & +2 & +2 & +2 \\
\hline B & +3 & -3 & 0 & 0 & +3 & 0 \\
\hline C & +3 & -3 & +3 & +3 & +3 & +3 \\
\hline D & +3 & 0 & +3 & -3 & +3 & +3 \\
\hline $\mathbf{E}$ & +1 & 0 & 0 & 0 & 0 & -1 \\
\hline $\mathbf{F}$ & +3 & -3 & -3 & 0 & +3 & -3 \\
\hline TOTAL & & -7 & 5 & 2 & 14 & 5 \\
\hline
\end{tabular}

Fonte: Elaborado por autoras de acordo com pesquisa realizada (2019)

Sendo assim, constatou-se que produto avaliado através da matriz de seleção de oportunidades possui pontos negativos quanto a estabilidade e é moderado em relação ao conforto do cesto, do preço e a compactação.

\section{Resultados e discussões}

A alternativa selecionada de guincho de transferência consiste em um produto que possa atender a atividade realizada de maneira segura e mais confortável, principalmente para o idoso. O conceito está atrelado a forma dos membros inferiores do flamingo, seu formato cilíndrico, com juntas circulares e o formato das patas, difere esteticamente dos produtos presentes no mercado, além de possuir sistema de compactação, permitindo a acomodação em carros ou locais menores.

Referente aos procedimentos metodológicos, foram analisadas as alternativas geradas, utilizando-se de técnicas como a prototipagem, na qual é feita a produção de um modelo 
tridimensional do produto a ser desenvolvido, e posteriormente, foi gerada a modelagem 3D (v. figura 18).

Figura 18 - Modelagem 3d e prototipagem
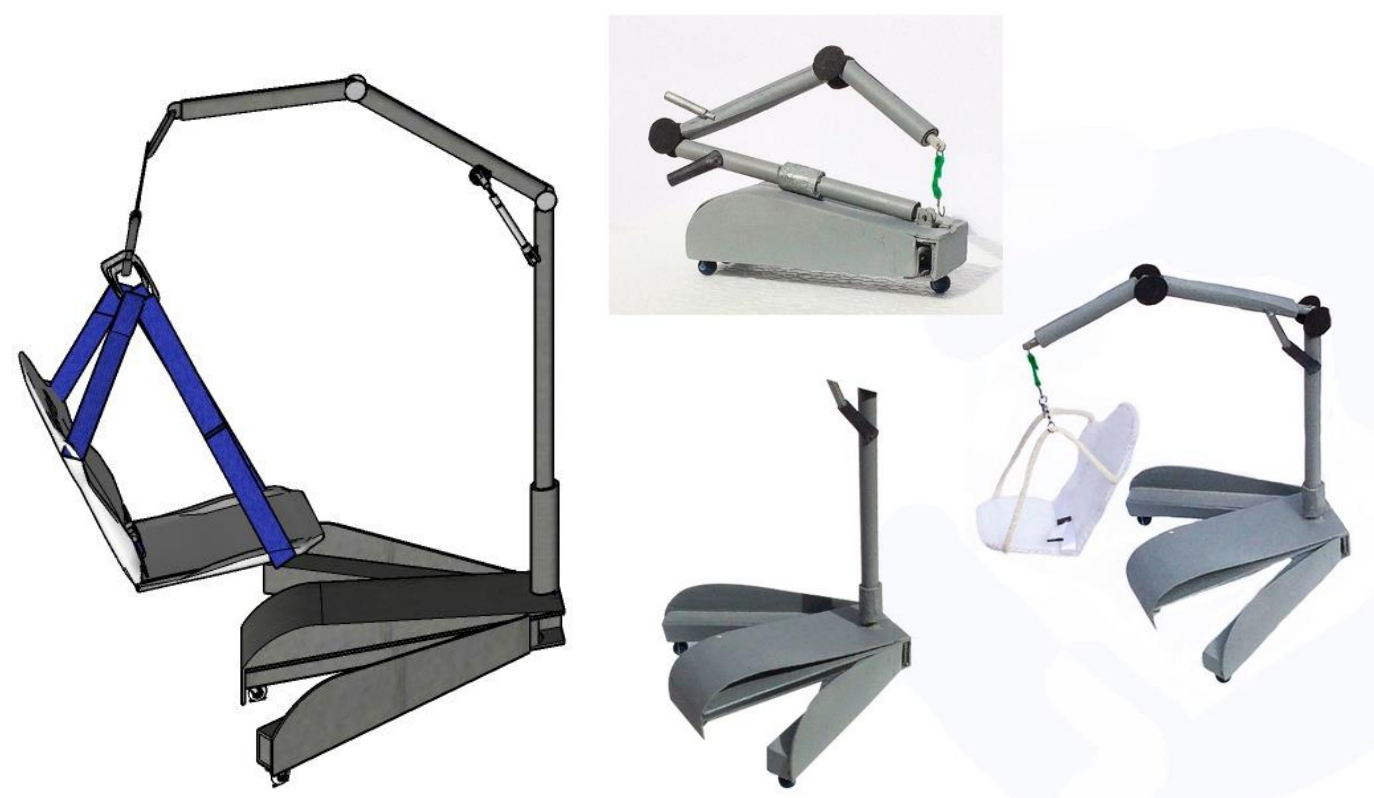

Fonte: Elaborado por autoras de acordo com pesquisa realizada (2019)

O guincho de transferência foi planejado com as seguintes dimensões gerais: $31 \times 100$ x 188 cm (comprimento, largura e altura) e por possuir sistema de compactação, pode apresentar as medidas de 31 x 167 x $67 \mathrm{~cm}$ (comprimento, largura e altura) quando dobrado (v. figuras 19 e 20).

Figura 19 - Dimensionamento geral e perspectiva explodida
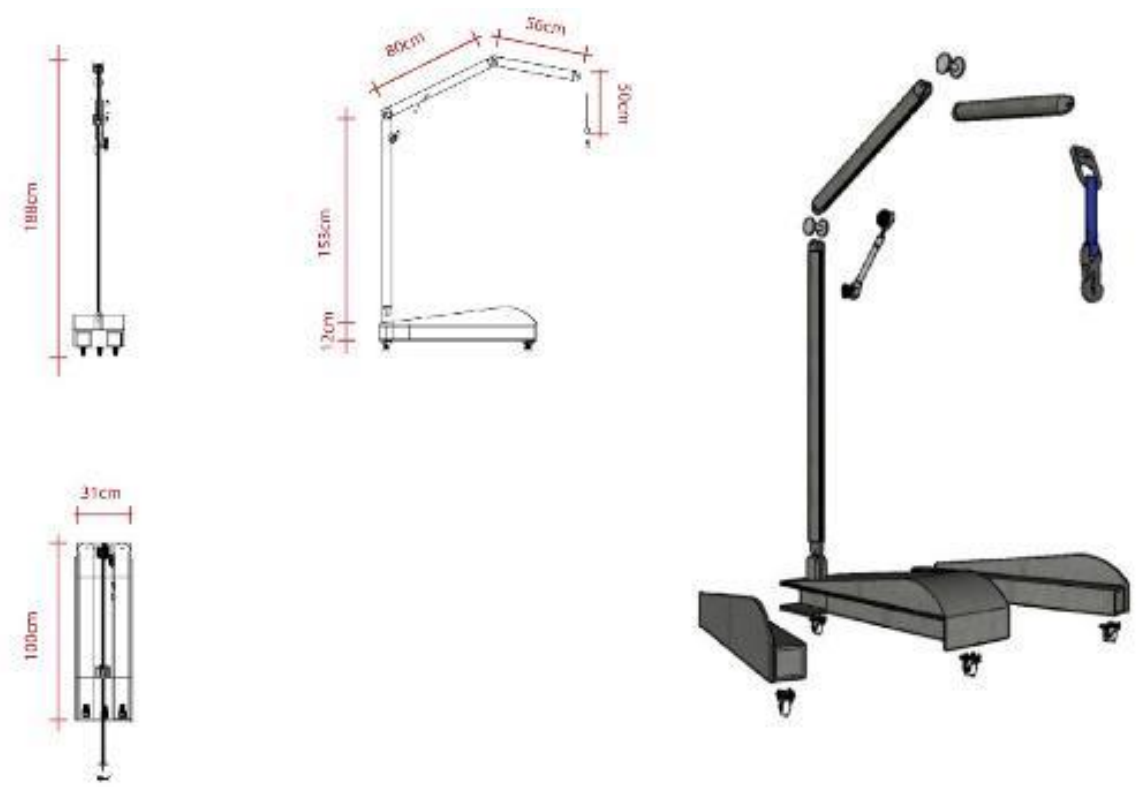


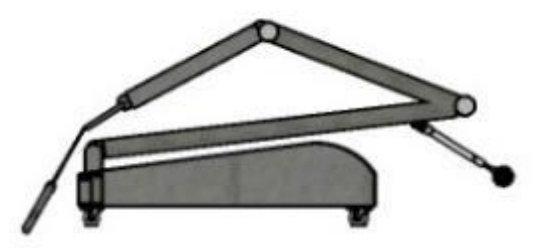

Fonte: Elaborado por autoras de acordo com pesquisa realizada (2019)

\section{Considerações finais}

Ao observar a necessidade de produtos voltados para a o público da terceira idade, que de forma geral não atendem às expectativas dos usuários, utilizou-se uma metodologia híbrida para auxiliar no desenvolvimento de um objeto acessível, ergonômico, seguro e confiável para o idoso e os cuidadores.

Desse modo, ao buscar e analisar informações acerca do tema, foi possível imergir na realidade de pessoas com mobilidade reduzida, a partir da aplicação de ferramentas metodológicas propostas por diversos autores, a fim de alcançar as metas definidas no primeiro contato com o público para o qual o projeto está sendo desenvolvido. E posteriormente, na etapa projetual, com base nos requisitos, foram geradas alternativas e selecionada a mais relevante.

O produto desenvolvido apresenta como diferencial as formas cilíndricas e arredondadas, baseando-se no estudo da biomimética, inspiradas no corpo do flamingo, animal que, para poupar energia, sustenta todo o peso do corpo em uma perna só. Além disso, outro ponto positivo é a sua possibilidade de compactação, permitindo maior facilidade ao guardar o produto e maior praticidade em transportá-lo para outro lugar.

Portanto, inserido no contexto do design inclusivo, o projeto destaca a importância do desenvolvimento de produtos que busquem melhorar as práticas de atividades cotidianas. Nesse viés, o design adentra em questões sociais que necessitam de maior atenção, desenvolvendo soluções para uma parcela da população que, muitas vezes, acaba passando despercebida.

\section{Referências}

Decreto no 5296, de 02 de dezembro de 2004. Regulamenta as Leis nos 10.048, de 8 de novembro de 2000, que dá prioridade de atendimento às pessoas que especifica, e 10.098, de 19 de dezembro de 2000, que estabelece normas gerais e critérios básicos para a promoção da acessibilidade das pessoas portadoras de deficiência ou com mobilidade reduzida, e dá outras providências. Diário Oficial da União República Federativa do Brasil, Brasília, DF, 02 dez. 2004. Disponível em: <http://www.planalto.gov.br/ccivil_03/_ato20042006/2004/decreto/d5296.htm>. Acessado em: 21 jan. 2019. 
BAXTER, M. Projeto de produto: guia prático para o projeto de novos produtos. São Paulo: Edgard Blucher, 2000.

BONSIEPE, Gui. (coord.). Metodologia experimental: desenho industrial. Brasília: CNPq/Coordenação editorial. 1984.

BROWN, Tim. Design Thinking: uma metodologia poderosa para decretar o fim das velhas idéias. Rio de Janeiro: Elsevier, 2010.

BUZAN, Tony. Mapas mentais. Rio de Janeiro: Sextante, 2009.

GOMES, Danila.; QUARESMA, Manuela. O contexto do design inclusivo em projetos de produto: ensino, prática e aceitação. In: Congresso brasileiro de pesquisa e desenvolvimento em design, 12., 2016, Belo Horizonte. Anais... Belo Horizonte: Universidade do Estado de Minas Gerais, 2016. p. 3144.

INSTITUTO de Pesquisa Econômica Aplicada. População idosa brasileira deve aumentar até 2060. Disponível em:

$<$ http://www.ipea.gov.br/portal/index.php?option=com_content\&view=article\&id=33875\&Ite mid=9>. Acesso em: 27 out. 2019.

KARSCH, U. Idosos dependentes: famílias e cuidadores. Rio de Janeiro, 2003.

KEPNER, Charles H.; TREGOE, Benjamin B. O administrador racional. São Paulo: Atlas, 1981.

KIM, W. C.; MAUBORGNE, R. Blue Ocean Strategy, Expanded Edition: How to Create Uncontested Market Space and Make the Competition Irrelevant. Boston: Harvard Business Review Press, 2004.

LIMA, A. M. Introdução aos materiais e processos para designers. Rio de Janeiro: Ciência moderna, 2006.

MACONEQUI. Acidentes com idosos: conheça os principais e saiba como evitá-los.

Disponível em: <https://blog.maconequi.com.br/acidentes-com-idosos/>. Acesso em: 22 nov. 2019.

MIRANDA, G. et al. O envelhecimento populacional brasileiro: desafios e consequências sociais atuais e futuras. Revista Brasileira de Geriatria e Gerontologia, Rio de Janeiro, 2016.

VIANNA, M. et al. Design thinking: inovação em negócios. Rio de Janeiro: MJV Press, 2012. 